\title{
Mundivisão proletária no cinema dos grupos Medvedkine
}

\section{Leonardo Gomes Esteves}

Doutor; Universidade Federal de Mato Grosso, Cuiabá, MT, Brasil

leonardogesteves@gmail.com

\section{Resumo}

O presente artigo investiga a safra inicial de filmes dos grupos Medvedkine, criados em Besançon e Sochaux nos entornos de 1968 e composto por operários. A análise toma como parâmetro o emprego de uma mundivisão proletária, tal como trazida pelo filósofo Herbert Marcuse em Contra-revolução e revolta (1973). Os filmes contemplados nesta revisão são Classe de lutte (1969) e Week-end à Sochaux (1972), correspondentes à safra inicial de obras produzidas pelos grupos. Na análise pretende-se abordar as convergências e discrepâncias entre a obra em questão e os preceitos vanguardistas, divididos entre protagonismo social e negação estética, de forma a delinear um quadro comparativo entre teoria e prática no ofício de cineasta desempenhado pelo proletário. Chega-se à conclusão de que há divergências entre o objeto aqui analisado e um projeto de cinema vanguardista elaborado no período.

\section{Palavras-chave}

Cinema francês. Vanguarda cinematográfica. Cinema militante. Grupos Medvedkine. Maio de 68.

\section{Introdução}

Onde o proletário for não-revolucionário, $a$ literatura revolucionária não será literatura proletária.

Herbert Marcuse

Fundados nos arredores de 1968 e marcados pela efervescência político-militante que emerge com fôlego no Maio de 68, os grupos Medvedkine resultam em uma experiência singular. Formados em duas regiões da França, primeiramente em Besançon e, depois, em Sochaux, estes grupos são constituídos por operários que passam a se interessar pela produção cinematográfica a partir do encontro com Chris Marker. A ocasião se dá a 
propósito da produção de À bientôt, j'espère (1967), rodado em Besançon por Marker e Mario Marret. Este documentário é filmado durante e sobre a greve na fábrica têxtil Rhodiacéta, em março de 1967. Depois de finalizado, é exibido aos trabalhadores que protagonizam o filme e é duramente criticado por eles.

A reprovação proletária consiste na falta de identificação entre os retratados e o retrato. Os operários alegam que a obra não os representa adequadamente. Incentivados por Marker, passam a receber aulas de cineastas como Jean-Luc Godard, Joris Ivens, René Vautier, entre outros, com a intenção de produzir seus próprios filmes - o que ocorre em seguida, sob o abrigo da produtora de Marker, S.L.O.N.

A filmografia produzida pelos operários se inicia em 1969 com o média-metragem Classe de lutte, do grupo Medvedkine de Besançon. A empreitada permanece em atividade até 1974 e os grupos produzem aproximadamente uma dúzia de títulos, entre curtas, médias e longas-metragens ${ }^{1}$. Como previsto, tal produção estará diretamente relacionada à questão proletária, abordando a rotina e o engajamento da classe. 0 cinema torna-se, então, para o operário, "ferramenta de conhecimento e tomada da palavra" (MUEL; MUEL-DREYFUS, 2008, p. 330, tradução nossa) ${ }^{2}$.

Ao pegar as câmeras e empregar o cinema como meio de expressão, muito está em jogo para os operários envolvidos neste projeto patrocinado por Chris Marker e apadrinhado por outros cineastas. A trajetória cinematográfica deste conjunto de trabalhadores ganha relevo enquanto um processo estruturado sobre duas instâncias. Uma na qual a prática em si é um espaço de descobertas e cuja afirmação se dá no fato, no fazer. Desta instância, incorpora-se a ideia de uma prise de parole cinematográfica do proletário restrita ao gesto, à condução de uma ferramenta-câmera de conhecimento, para contextualizar a fala de Bruno Muel e Francine Muel-Dreyfus (2008) reproduzida acima. E a outra instância diz respeito àquilo que é feito a partir deste fazer, ou seja, refere-se ao filme enquanto objeto acabado, discurso cinematográfico.

Há, portanto, dois sentidos que visam legitimar tal empreitada nos termos de uma vanguarda, colocando em relevo a excepcionalidade do evento em si. Há uma afirmação social, para a qual o fato de que operários estejam empregando câmeras-ferramentas cinematográficas descortine um novo quadro - o que poderia corresponder a uma vanguarda no cinema. E há uma afirmação formal, proveniente desta prática, no corpo do filme - e que poderia ser designado como um cinema de vanguarda. Pode-se falar, logo, em

\footnotetext{
1 Da parte do grupo Medvedkine de Besançon, a seguinte filmografia é produzida: Classe de lutte, Rhodia 4X8, Nouvelle Société no 5 (Kelton), Nouvelle Société no 6 (Biscuiterie Buhler) e Nouvelle Société no 7 (Augé Découpage), todos de 1969, e Le traîneau-échelle e Lettre à mon ami Pol Cèbe, ambos de 1971. Da parte de Sochaux: Sochaux, 11 juin 1968, de 1970, Les 3/4 de la vie, de 1971, Week-end à Sochaux (1972), Septembre chilien, de 1973, e Avec le sang des autres, de1974.

2 No original: "Outil de connaissance et de prise de parole".
} 
um âmbito político-social e outro estético, que irão definir, ou redefinir, certa ordem de prioridades no processo produtivo.

Os grupos Medvedkine seriam, portanto, um objeto privilegiado para a investigação de uma aplicação do conceito de vanguarda tal como proposto acima. Pois, para Bürger (2008), a vanguarda deveria responder a uma dupla significação, enquanto ataque à instituição arte e surgimento de um tipo de obra de arte que não é orgânica. No cinema, Albera (2012, p. 58) vai reafirmar duas instâncias para a vanguarda: o objeto deveria estar habilitado a marcar uma posição no campo artístico que é elemento de uma política interna e externa. Isto é, entre uma instância político-social e outra artística. 0 que quer dizer que a atividade passa a ser vista não apenas como "porta-voz do movimento, [...] vanguarda da luta social ou a vanguarda da sociedade" (para o exemplo citado aqui, operários na criação do cinema), mas, também, "sobre a base da autonomização da arte e da constituição de um campo artístico, a arte de vanguarda está na vanguarda da arte" (ALBERA, 2012, p. 70, grifo do autor).

A vanguarda poderia, portanto, ser dimensionada em duas instâncias, tal como proposto acima: pode-se falar em vanguarda no cinema e cinema de vanguarda. A vanguarda no cinema estaria restrita à abordagem de um tema social, o compromisso com causas referentes à vanguarda da sociedade. Poderia se dar tanto em um sentido temático (filmes sobre a causa operária ou retratos sobre as minorias sociais) quanto em um sentido factual (filmes nos quais operários ou minorias exercem seus direitos de expressão, para além de servir apenas como modelo). Já um cinema de vanguarda se daria em um sentido estético, ao delimitar um campo no interior da arte, a partir da criação de obras nãoorgânicas ${ }^{3}$. Isto é, não está necessariamente tratando sobre uma vanguarda que chacoalhe os valores sociais de uma sociedade, mas sim sobre os valores estéticos das tradições artísticas operantes na sociedade. Em resumo: a vanguarda na arte é referente a uma movimentação social ou à identidade de uma produção; a arte de vanguarda versa sobre o objeto artístico produzido.

É a partir desses dados introdutórios em torno dos grupos Medvedkine e de uma identidade vanguardista supostamente dual que este artigo pretende analisar a produção

\footnotetext{
3 "A obra orgânica está identificada com a integração de todos os aspectos, de forma a salientar uma totalidade - para o qual as partes estão interligadas e confirmam um todo, o que, em última análise, responderia por uma reprodução da realidade. Já a obra não-orgânica é fragmentária. A estrutura sintagmática na qual as partes individuais e o todo formariam uma dialética, se veria, logo, solapada na obra não-orgânica. Nesta modalidade, as partes se emancipariam de um todo; trata-se de uma obra composta mais pela realidade do fragmento do que pelo fragmento da realidade. "O artista que produz uma obra orgânica [...] manipula seu material como algo vivo, cuja significação, advinda de situações concretas de vida, ele respeita. Para o vanguardista, ao contrário, o material é apenas material. Sua atividade, afinal, não consiste senão em matar a 'vida' do material, isto é, arrancá-lo ao seu contexto funcional, que é o que lhe empresta significado [...] Em conformidade com isso, o clássico trata seu material como totalidade, enquanto o vanguardista arranca o seu à totalidade da vida, isola-o, fragmenta-o." (BÜRGER, 2008, p. 129).
} 
inicial do objeto. Para esta análise, o termo mundivisão proletária - que é incorporado por Herbert Marcuse em sua obra na contemporaneidade dos debates pós-68, revitalizando uma discussão já longínqua em torno da concepção de uma arte proletária - se faz necessário. Com essa expressão, Marcuse (1973) compreende contemplar "a visão do mundo que predomina na classe trabalhadora" (MARCUSE, 1973, p. 120). Para ela, contudo, resta ainda um impasse no campo artístico: "Uma literatura revolucionária em que a classe trabalhadora é o tema e que seja a herdeira histórica, a negação definitiva, da literatura 'burguesa', continua sendo uma coisa do futuro." (MARCUSE, 1973, p. 123). O presente trabalho pretende, portanto, analisar a filmografia inicial dos grupos Medvedkine enquanto proposta de cinema revolucionário. Neste caso, cabe considerar o trânsito do objeto entre duas instâncias, o protagonismo (vanguarda no cinema) e a negação definitiva do cinema burguês (cinema de vanguarda), visando apontar convergências e discrepâncias.

\section{Mundivisão proletária na arte}

A produção dos grupos Medvedkine transpõe, a rigor, para o contexto do cinema militante pós-Maio de 68 a gênese de um debate que ocupou a intelligentsia alemã dos anos 1920/1930 no campo da literatura. Este é o da possibilidade e do significado de uma arte proletária, tomando como base a questão da representação. No caso dos alemães, trata-se de uma literatura proletária, originária da classe trabalhadora, que divide Lukács, Andor Gabor e J. R. Becher de um lado, e, de outro, Brecht, Walter Benjamin e Ernest Bloch ${ }^{4}$.

A rixa entre as duas correntes se dá na questão estilística que emerge em torno da estética jornalística. Lukács ataca escritores em sintonia com Brecht, como Willy Bredel e Ernst Ottwalt, que buscavam suprimir a ficção apoiados em técnicas de reportagem, que fragmentavam a realidade. Para o autor de História e consciência de classe, o estilo reportagem não visaria sensibilizar o leitor, e, portanto, não poderia ser considerado como literário. A distinção entre finalidade científica e artística, a qual Lukács apoia abertamente, faria com que a reportagem fosse inútil em uma aplicação literária - pois seria, em gênese, científica. Pior, seu emprego ainda acusaria as vísceras, as engrenagens do processo narrativo, o que a literatura ideológica se esforçaria por ocultar de forma permanente. $\mathrm{Ou}$ seja, Lukács está ainda apegado à construção do enredo, à totalidade da obra sobre as partes que a compõe, e, em última análise, à verossimilhança, ao naturalismo, à impressão de realidade, à obra orgânica. Identifica-se ao que se denominou acima como vanguarda no

4 A obra de Helga Gallas, Marxistische Literaturtheorie, traduzida para o italiano e para o espanhol, aborda o episódio e serve como referência para Marcuse em Contra-revolução e revolta. Baseio as informações deste livro na tese de Renato Bueno Franco (1992), que também recorre à obra de Gallas. 
cinema. É desnecessário apontar a distância entre essa visão e a de Brecht em muitos sentidos. No caso do emprego de elementos da reportagem, nota-se, mais uma vez, a perspectiva de romper com a ilusão, como na técnica do estranhamento. Isto é, perturbar a fruição natural da obra pelo leitor.

Neste já consagrado debate no qual se opõe tradicionalismo e novas formas de expressão, Marcuse (1973) aponta uma defasagem em relação aos tempos então atuais (1972 é data da publicação original de Contra-revolução e revolta). É que, com o desenvolvimento da arte, ou melhor, da anti-arte, a obra de Brecht teria tornado-se tradicional. Para este argumento, o da entrada de Brecht em um chamado establishment revolucionário $^{5}$, o trabalho de Godard e Jean-Pierre Gorin em Tudo vai bem (1972), um exemplar da influência do Maio de 68 sobre o cinema, poderá servir como uma referência singular ${ }^{6}$. 0 que, entretanto, teria permanecido relevante, a ponto de figurar com certo destaque nos apontamentos de Marcuse (1973), seria o conceito de "mundivisão

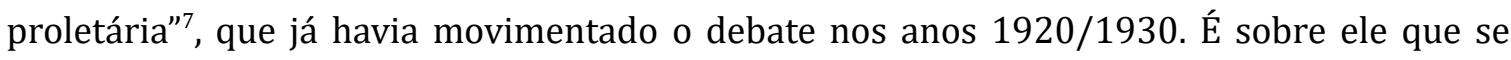
concentra a questão "do significado e a da própria possibilidade de uma 'literatura proletária"' (MARCUSE, 1973, p. 119), que se busca transpor aqui para a discussão do "cinema proletário", tomando como base uma fração da filmografia dos grupos Medvedkine. Discorre-se, portanto, sobre a possibilidade de uma arte proletária que congregue em si uma concepção proletária de mundo. Observa Helga Gallas, na contemporaneidade de Marcuse (e citada por ele, para o qual o debate dos anos 1920/1930 representava ainda, em 1972, o ápice das discussões sobre o assunto):

Em relação à literatura proletária [...] a existência de uma mundivisão proletária vem pressuposta. Mas é precisamente essa suposição que não resiste a uma verificação ainda que breve. É verdade que na sociedade capitalista atual existe uma classe proletária ou proletarizada que no meio tempo abraça $80 \%$ da população e que é constituída não só de operários, mas também de empregados - pressuposto que o conceito de classe proletária se orienta com base na disposição ou não disposição sobre os

\footnotetext{
5 Tomo a expressão "establishment revolucionário" emprestada de Marcuse (2002), que observa que "[...] a arte pode cumprir sua função revolucionária interna somente se ela própria não se torna parte de qualquer establishment, inclusive o establishment revolucionário." (MARCUSE, 2002, p. 261).

6 Produzido ainda em torno do período militante no qual o cineasta fundou ao lado de Gorin e outros o grupo Dziga Vertov, Tudo vai bem (1972) é o filme de maior investimento, atores famosos (Yves Montand, Jane Fonda), produção na bitola 35mm, fatores que teriam suscitado inúmeras críticas. A radicalidade da filmografia em $16 \mathrm{~mm}$ produzida pelo grupo teria sido amenizada nesta reflexão mainstream sobre a França pós-68.

7 Esta expressão é retirada da obra de Helga Gallas, publicada originalmente em alemão, em 1971 (edição que fora consultada por Marcuse). Na edição original, em inglês, de Contra-revolução e revolta, lê-se "proletarian world view". Na edição em italiano da obra de Gallas (1974), no trecho que Marcuse reproduz em seu trabalho, a expressão vem traduzida como "concezione del mondo proletario"/ "concepção de mundo proletário". Optei por manter a expressão tal como se deu na tradução brasileira. É importante observar que nesta mesma edição, ao reproduzir o trecho original de Gallas, o tradutor (Álvaro Cabral) optou por não repetir "mundivisão proletária", e sim “visão proletária do mundo" (MARCUSE, 1973, p. 120). Na tradução que eu fiz a partir da versão italiana, logo adiante, optei por manter "mundivisão proletária", respeitando a uniformização que se dá no original em inglês, "prolertarian world view".
} 
meios de produção. Mas não ocorre incomodar Marx para constatar que no interior da sociedade capitalista alienada é impossível falar de uma mundivisão proletária de qualquer modo comparável àquela burguesa, e o é também em relação à parte politicamente consciente daqueles que são economicamente e socialmente dependentes. Lukács evitou o problema da experiência de classe proletária e da relativa formação de uma ideologia, transformando já nas suas contribuições 'Linkskurve' o conceito de 'mundivisão proletária' naquele de uma 'concepção de mundo marxista' generalizada e que não implicava necessariamente a experiência de classe. (GALLAS, 1974, p. 100, tradução nossa) ${ }^{8}$.

Redimensionada para os entornos de 1968, a questão ainda parece relevante. 0 descompasso entre arte e mundivisão proletária poderia ser notado sem dificuldades pelo projeto de cinema marxista de vanguarda encampado pela crítica de cinema francesa do período e sua posição referente à produção dos grupos Medvedkine. "Nós jamais consideramos o grupo Medvedkine no movimento revolucionário, mas na tradição anarcosindicalista." ${ }^{9}$ (LEBLANC, 2017), observa Gérard Leblanc, crítico fundador de Cinéthique. Neste distanciamento do projeto operário em torno dos grupos Medvedkine, o muito celebrado debate estético travado entre Cahiers du cinéma, Cinéthique e Nouvelle critique ${ }^{10}$ estaria ainda imerso em uma lacuna histórica. É novamente reproduzida a problemática tentativa de legitimar a desconstrução da representação desarticulada de uma expressão genuinamente proletária. A brecha intocada por Lukács e Brecht em suas defesas estéticoliterárias torna a se apresentar nas desconstruções do cinema motivadas pelos althusserianos que visam entronizar pela crítica um inventário materialista no cinema militante. Como coloca Gallas (1974), a transposição de uma "mundivisão proletária" para a "concepção de mundo marxista", operada pelos intelectuais, torna a "experiência de classe" facultativa. Na mesma linha se dá a questão da ideologia com Althusser e o cientificismo pregado por ele e problematizada por Rancière $(2011)^{11}$; e com a prática teórica que é conduzida pela crítica de cinema no pós-Maio, citada acima, um desdobramento da influência de Althusser no período.

\footnotetext{
8 No original: Rispetto alla letteratura proletaria [...] l'esistenza di una concezione del mondo proletario viene presupposta. Ma è appunto questo presupposto che non regge a una verifica sia pure sommaria. È vero che nella società capitalista attuale esiste una classe proletaria o proletarizzata che nel frattempo abbraccia l'80\% della popolazione e che è constituita non solo da operai ma anche da impiegati - presupposto che il concetto di classe proletaria si orienti in base alla disposizione o non disposizione sui mezzi di produzione. Ma non occorre incomodare Marx per constatare che all'interno della società capitalista estraniata è impossibile parlare di una concezione del mondo proletaria in qualche modo paragonabile a quella borghese, e lo è anche rispetto alla parte politicamente consapevole di coloro che sono economicamente e socialmente dipendenti. Lukács evitò il problema dell'esperienza di classe proletaria e della relativa formazione di un'ideologia, transformando già nei suoi contributi a 'Linkskurve' il concetto di 'concezione del mondo proletaria' in quello di una 'concezione del mondo marxista' generalizzante e che non implicava necessariamente l'esperienza di classe.

9 No original: “Nous n'avons jamais considéré que le groupe Medvekine se situait dans la mouvance révolutionnaire mais dans la tradition anarcho-syndicaliste.".

${ }^{10}$ Para um aprofundamento sobre este episódio ver: Esteves (2018) e Xavier (2005).
} 
Já no projeto em torno dos grupos Medvedkine, a mundivisão proletária com experiência de classe seria, a princípio, obrigatória, pois os filmes são oriundos da classe. Mas outra problemática surge daí: a da ligação destes operários com a classe artística, burguesa, que está, desde o início, matizada na identidade dos grupos. Da resposta a um filme sobre o qual teria sido reivindicada justamente a ausência da mundivisão proletária pela própria classe (À bientôt, j'espère) à iniciação prática fornecida pelos cineastas profissionais (Marker, Godard, Ivens, entre outros), o contágio é inevitável. A questão da mundivisão proletária na obra dos grupos Medvedkine poderá ser questionada, colocada em xeque. Sobretudo, em um aspecto estético, formal, pois ele faz transparecer uma descaracterização que pode ser justificada como que emergente da experiência entre classes, resultando em um questionamento sobre a autenticidade do que seria mundivisão proletária.

Se a expressão mundivisão proletária quer significar a visão do mundo que predomina na classe trabalhadora, então trata-se, nos países capitalistas avançados, de uma visão do mundo que é compartilhada por uma considerável parte das outras classes, especialmente as classes médias. ( $\mathrm{Na}$ linguagem marxista ritualizada, chamar-se-lhe-ia consciência reformista pequeno-burguesa). (MARCUSE, 1973, p. 120).

Os filmes iniciais dos grupos Medvedkine de Besançon e Sochaux abrem os trabalhos em torno de uma mundivisão proletária no cinema militante pós-Maio, mas nesta obra as ambições não parecem tão longe da perspectiva burguesa. Não estariam aí replicando uma “consciência reformista pequeno-burguesa" proveniente da classe-média que provocou e capacitou o cinema proletário em questão? Tal ideia parece estar entranhada no discurso de um dos jovens operários que falam em Week-end à Sochaux (1972): “O cinema pode se tornar uma arma valiosa para o proletariado, pois ele já provou que é uma arma eficaz para a burguesia. ${ }^{\prime 2}$. Mas o que dizem os filmes enquanto discurso cinematográfico?

\footnotetext{
${ }^{11}$ Rancière publica em 1969 um longo artigo, Sur la théorie de l'idéologie: politique d'Althusser, mais tarde incluído no livro La leçon d'Althusser (originalmente publicado em 1974), no qual acusa Althusser de revisionista, oportunista. A crítica se dá no momento em que os comentários do filósofo passaram a justificar a defesa do saber acadêmico. Na base da questão está a configuração dada à ideologia por Althusser. A função geral do termo implicaria em um quadro que intensifica a dominação da classe burguesa e atribui à força que tende a subvertê-la o status de ciência. Dessa forma, a ideologia se torna o Outro da ciência e esta, o Outro da ideologia. Tal homologia configuraria uma tradição metafísica, que passa a desprezar os domínios que consideram o discurso verdadeiro (ciência) e o falso (opiniões, erros, etc.). "A função geral da ideologia será colocada como que se exercitando em benefício de uma dominação de classe e a função de subversão desta dominação será conferida ao Outro da ideologia, quer dizer, a Ciência" (tradução nossa)/ "La fonction générale de l'idéologie sera posée comme s'exerçant au profit d'une domination de classe et la fonction de subversion de cette domination sera conférée à l'Autre de l'idéologie, c'est-à-dire la Science" (RANCIÈRE, 2011, p. 225).

${ }^{12}$ No original: "le cinéma peut devenir une arme valable pour le prolétariat, puisqu'il est déjà prouvé qu'il est une arme efficace pour la bourgeoisie."
} 


\section{Classe de lutte e Week-end à Sochaux}

Se o cinema é uma arma eficaz para a burguesia, de que maneira ele poderia sê-lo para o proletariado, como é proposto no filme do grupo Medvedkine de Sochaux? A resposta pode não ser tão simples se levado em consideração o resultado da produção, que torna irreconciliável a questão do protagonismo com o a da "negação definitiva" do cinema burguês, tal como apontado por Marcuse (1973) no campo literário, citado acima. Pode-se começar a discorrer sobre a identificação (e não negação) entre o cinema do proletário e o cinema burguês a partir do ponto de vista estético. 0 escopo ficará delimitado entre Classe de lutte, do grupo de Besançon, e Week-end à Sochaux, de Sochaux, pois são obras que pertencem à fatura inaugural das duas partes, correspondendo, portanto, ao impulso inicial da empreitada.

A câmera de Classe de lutte orbita em torno de Suzanne Zedet. A operária despolitizada que dá depoimento em À bientôt j'espère ressurge, dois anos mais tarde, recuperada pela militância. É seu rosto que abre o filme, preenchendo toda a dimensão do plano, e sobre a qual se sustenta a sequência inicial. O cotidiano de Suzanne se dá entre a militância (acompanhar a reprodução de panfletos e distribuí-los, frequentar a montagem/ produção de filmes), o trabalho e a vida em família. Ao final desta sequência (que se dá ao embalo de uma canção) uma voz em off a pergunta: "O que você faz?". Suzanne interrompe a datilografia e responde sorrindo: "milito". Esta sequência introdutória deixa clara a distância entre a mundivisão proletária, que faz ver justamente a experiência de classe genuinamente proletária, e a concepção marxista apregoada à época pela crítica: a divergência se dá pela via estética.

A "experiência de classe" que é mostrada nos minutos iniciais de Classe de lutte não corresponde ao "cinema direto" ou ao filme materialista dialético, dois conceitos que protagonizam o ápice das discussões entre Cahiers e Cinéthique ${ }^{13}$. Ela é diegética. Conta inclusive com um acompanhamento musical que emudece os fragmentos da rotina e imprime um tom contagiante, de celebração. Suzanne é em si uma protagonista no filme, o que já poderia ser considerado como um recurso burguês, que se choca prontamente com o anonimato visado pela leva mais engajada do cinema desconstrutor patrocinado pela crítica $^{14}$. Visto por esse ângulo, em Classe de lutte o peso do Maio de 68 enquanto agente mobilizador coletivo, divisor de águas, é redimensionado para a carga individual. Fica

\footnotetext{
${ }^{13}$ Para um aprofundamento sobre estes conceitos, ver Esteves (2018).

14 Tomo como uma referência radical, nesse sentido, a experiência de Godard pré-grupo Dziga Vertov, Un film comme les autres, que rechaça a ideia de individualidade e protagonismo ao filmar um grupo de estudantes e operários que debate anonimamente sobre assuntos emergenciais da pauta 68.
} 
restrito à experiência de Suzanne. Desta forma, as imagens do evento reforçam a presença da operária e sublinham o caminho da sua transformação pessoal. Há igualmente o narrador onipresente, cuja voz masculina surge eventualmente em over para fornecer informações pontuais e preencher lacunas narrativas.

A expressão que aparece grafitada na parede do ambiente onde se produz cinema com "mundivisão proletária" no início de Classe de lutte prevê a distância de um cinema ilusionista: "O cinema não é uma magia, ele é uma técnica e uma ciência; uma técnica nascida de uma ciência e colocada a serviço de uma vontade: a vontade que os trabalhadores têm de se libertar." (CLASSE..., 1969) ${ }^{15}$. Tal frase poderia representar uma espécie de marco teórico para este cinema operário, um lema levado ao pé da letra pela desconstrução estética formulada pelo filme. Tais palavras, contudo, parecem diluídas no discurso empregado. A técnica científica utilizada para construir o processo mágico no qual Suzanne passa a militar em favor da causa operária pouco se reporta à prática teórica marxista-leninista que está tramitando pela crítica no mesmo período - e que constitui um sólido respaldo para tal argumento anti-ilusionista. A magia se dá justamente no ocultamento dos signos que possibilitariam tal narrativa: a condensação dos melhores momentos da rotina embalados por uma canção; e uma direção política sintetizada em apenas uma pergunta-resposta, a militância. Trabalha-se sobre uma caricatura bem construída. Não haveria muito para o espectador decifrar nesta introdução ao cinema proletário, como propõe, por exemplo, a diretriz do filme materialista dialético ${ }^{16}$.

Já ao fim de Classe de lutte, a questão do aprimoramento cultural aporta outra informação importante à "mundivisão proletária”. Suzanne está sendo entrevistada por Pol Cèbe, importante agente da empreitada Medvedkine, que está em off. Suzanne declara que a arte não poderá estar restrita apenas à burguesia, distante da classe operária, como acreditava o ser anteriormente. Fala-se sobre Picasso e a figura do pintor assume um papel importante, nada aleatório. É que Suzanne está se expressando em um plano médio, no qual se vê apenas o vestígio do que, no enquadramento mais aberto, irá se desdobrar na reprodução de um dos portraits de Sylvette David. Para Foltz (2001), o paralelismo entre a reprodução cubista (multifacetada) e a própria Suzanne agrega uma identidade a Classe de lutte. Assim como o retrato feito por Picasso expõe as diversas faces e possibilidades de Sylvette, o filme do grupo Medvedkine revelaria operação semelhante em torno de Suzanne.

\footnotetext{
${ }^{15}$ No original: “Le cinéma n'est pas une magie, c'est une technique et une science; une technique née d'une science et mise au servisse d'une volonté: la volonté qu'ont les travailleurs de se libérer".

16 “[...] sendo dado que o filme não é um objeto mágico que age por fluido, graça ou virtude, este funcionamento dialético para ser efetivo é submetido a uma condição: que da parte do 'espectador' haja trabalho - decifração, leitura dos traços produzidos pelo trabalho do filme.” / “[...] étant donné que le film n'est pas un objet magique qui agit par fluide, gràce ou vertu, ce fonctionnement dialectique pour être effectif est soumis à une condition: que de la part du 'spectateur' il y ait travail - déchiffrement, lecture des traces produites par le travail du film." (FARGIER, 1969, p. 21).
} 
O processo poderia ser notado já na sequência de abertura, ao confrontar a Suzanne daquele instante com outra, do passado, reproduzida na pequena tela da mesa de montagem ${ }^{17}$.

Ao final do depoimento de Suzanne sobre a cultura, ela informa ter lido $A$ mãe, de Máximo Gorki, primeiro livro de que teria gostado. E assim se encerra Classe de lutte, em um inventário improvisado do repertório cultural que se vê estimulado pela inclinação militante pós-Maio de 68. Se há uma ameaça explícita ao final de À bientôt j’espère, no qual o proletário anuncia em tom desafiador a dominação do patrão ("on les aura" / "nós os teremos"), há outro tom neste média-metragem - que é tido como uma espécie de continuação do primeiro. A militância de Suzanne, tal como a mesma informa na sequência inicial, é algo aparentemente prazeroso, que evoca o sorriso ${ }^{18}$. E talvez resida aí um posicionamento mais ameno, que não implique na pura hostilização do patrão, mas possivelmente na tentativa de alcançá-lo e, no final, soar como ele. A opção por não apenas falar sobre Picasso, mas enquadrar sua obra no mesmo plano, poderá habilitar outras questões.

Se Foltz (2001) é feliz em apontar um paralelismo estrutural, que irá sinalizar para uma subjetividade que se vê estimulada por um contexto artístico-estético, Classe de lutte como um todo vai querer reverberar este contexto. Mas em outra chave, que vê o trabalho de Picasso apenas como um ícone simbólico da grande arte, um modelo a se inspirar. A intenção de propor Suzanne enquanto releitura da abordagem prismática de Sylvette vai, por si só, justificar a ambição deste filme em querer ser arte, em buscar se submeter a uma conversação que irá habilitar sua entrada no mundo das artes. E aí se dá a grande distância do cinema marxista vigente à época, que justamente está propondo rejeitar o cinema enquanto arte. A menção a Picasso em Classe de lutte é primeiramente trazida pela voz off de Pol Cèbe. É sua intenção não apenas apontar que Suzanne está evoluindo, mas que o próprio filme poderá ser visto como uma parcela desta evolução, ao enquadrar a obra em cena. Ou seja, a arte está agora ao alcance do proletário, ela compartilha a mesma imagem com ele. E mais do que isso: o proletariado poderá se expressar por meio dela. Poderá propor analogias

\footnotetext{
17 "O quadro reproduzido revela a outra intenção do filme. Por este jogo duplo sobre as formas, os autores de Classe de lutte indicam que domínio eles têm do cinema, quanto eles sabem o que se permite, em termos de manipulações, de reversões, de experimentações, de multiplicação de sentido. 0 todo consiste em o dizer, e isto desde os pré-créditos: em sua primeira entrada em cena, Suzanne se encaminha em direção a Simone Nedjma, que está trabalhando, e se vê na tela da mesa de montagem, Revelando seu fora de quadro, signo elementar da mise-en-abyme, o filme não se esquece de assinalar que surge como uma proposição particular, uma interpretação contingente da realidade, obra de um ponto de vista subjetivo." / "Le tableau reproduit découvre l'autre intention du film. Par ce double jeu sur les formes, les auteurs de Classe de lutte indiquent quelle maîtrise ils possèdent du cinéma, combien ils savent ce qu'il permet, en termes de manipulations, de renversements, d'expérimentations, de multiplication des sens. Le tout consiste à le dire, et ce dès le pré-générique: à sa première entrée dans le champ, Suzanne s'avance vers Simone Nedjma en train de travailler et se voit sur l'écran de la table de montage. En révélant son hors-cadre, signe élémentaire de la mise en abyme, le film n'oublie pas de signaler qu'il advient comme une proposition particulière, une interprétation contingente de la réalité, l'œuvre d'un point de vue subjectif" (FOLTZ, 2001, p. 88-89).

${ }^{18}$ Sobre esse dado, Comolli (2001) observa: "Aqui, riso e luta andam junto, nos combates mais difíceis, quebra da diversão." / "Voilà, rire et lutte vont ensemble, dans les combats les plus rudes, effraction de la drôlerie." (COMOLLI, 2001, p. 38).
} 
com a história da arte e suas alegorias, flertar com seus desvios estetizantes e suas aberrações que visaram interromper a magia sedimentada pela representação objetiva, naturalista.

Por outro lado, cabe apontar uma intenção bem diferente nos planos que visam enquadrar Guernica em dois filmes de Godard/grupo Dziga Vertov. Em British sounds (1969), o grande expoente da fase cubista de Picasso está replicado em uma parede, adornando um debate entre operários. Em Ici et ailleurs (1974) a reprodução do quadro está decorando a casa de uma família de classe-média. Em ambos os casos a crítica parece ser a mesma. Isto é, aponta-se à domesticação da arte, o esvaziamento de seu sentido, à perda de seu potencial deformador, enfim, à sua racionalização. Diferente de Classe de lutte, no qual a obra de Picasso faz ainda alusão ao fazer (boa) arte, em Godard, Guernica serve para apontar a morte da arte, sua inutilidade, indiferença, sua incorporação a qualquer contexto - comentário afinado à crítica de Benjamin sobre a perda da aura pela via da reprodutibilidade técnica. A finalidade estéril da mera decoração despropositada e descontextualizada das vanguardas artísticas é a pauta que escapa às aspirações da obra do grupo Medvedkine de Besançon. De forma mais genérica, a comparação entre Godard/ grupo Dziga Vertov e grupo Medvedkine de Besançon a partir da referência à(s) obra(s) de arte (de Picasso) revela dois movimentos/aspirações. Enquanto o primeiro utiliza a obra de arte enquanto objeto para meditar sobre a morte de uma cultura, ensejando uma desvinculação com o mundo do espetáculo, o segundo toma (a reprodução) do quadro uma metáfora do ingresso, do desejo de pertencimento.

Week-end à Sochaux, ou mesmo o projeto embrião Les trois-quarts de la vie, vai caminhar em um sentido similar a Classe de lutte. A forte pegada documental que emoldura o processo evolutivo de Suzanne tem menos intensidade nesta obra, que vai enfatizar uma encenação satírica, visando denunciar os abusos e condições desfavoráveis dos operários na linha de montagem da Peugeot (encenados por eles mesmos). Neste projeto é igualmente notória a vontade de legitimar um cinema operário. A finalidade talvez não seja tão ambiciosa, como se vê em um dos depoimentos: a de ocupar o mesmo debate das segundasfeiras na usina; mas ao invés de falar sobre um filme burguês visto no final de semana, debater-se-ia sobre um filme operário. De toda forma, a estrutura narrativa do filme não impõe transgressões à forma tradicional de contar histórias. Chega-se a associar um leitmotiv musical (melodia cantarolada em assovio) para os momentos repetitivos no qual o mesmo operário é desalojado de moradias temporárias.

Ao término de Week-end a Sochaux, a câmera acompanha uma jovem operária que perambula por uma via deserta e faz previsões sobre o futuro. Neste, haverá uma inversão. 
Os chefes terão as atribulações de seus inferiores na linha de montagem; as casas serão todas fraternas, não vai haver mais chaves; e o dinheiro será suprimido, informa ela. Ou seja, não haverá diferença de classes e tudo estará ao alcance de todos. 0 plano é encerrado com a imagem congelada da operária - procedimento que, na história então recente do cinema moderno francês, marca a safra inicial da Nouvelle Vague. Este congelamento insiste sobre a permanência do presente que é a atualidade do filme, a prise de parole cinematográfica do proletário. A moldura estática está, contudo, forjando uma natureza paradoxal. A da produção de um documento militante, reservado ao presente do seu registro (e encerrado nele?); mas também a da vocação artística, para a qual as palavras de Bazin (2014) sobre a ontologia da imagem fotográfica poderiam se adequar sem grandes esforços ${ }^{19} .0$ crédito de Week-end à Sochaux o encaminha para essa natureza atravessada, que fala sobre o concreto, mas visa a confrontá-lo de forma poética, lúdica, encenada: “Um filme escrito, apresentado e sonhado pelo grupo Medvedkine de Sochaux" (WEEK-END..., 1972) ${ }^{20}$. Não deixa de simbolizar para um presente que é um sonho, irreal, utópico.

Ao término de Classe de lutte, logo após um zoom sobre o rosto de Suzanne, se lê "à suivre" / "a continuar"; Week-end à Sochaux interrompe as previsões para o futuro da operária anônima com a permanência do instante. Há, aí, neste percurso, um impasse que mantém em suspenso duas formas de colocar no presente uma projeção para o futuro. Neste impasse, o que é visado é uma igualização de classes. Ela se dá pelo conteúdo do discurso, que é explícito. Mas se dá, também, e, sobretudo, pelo aspecto estético destes filmes, pela narrativa convencional que empregam.

A presença feminina, que nos dois términos é decisiva, é outra forma de propor a igualdade. Ela tira das mãos do homem certo protagonismo histórico (igualização de gêneros). Faz coro à célebre pintura de Delacroix ( $A$ liberdade guiando o povo) reinterpretada na iconografia do Maio de $68^{21}$, na qual a mulher lidera a revolução, guiando o povo entre as barricadas. Tal projeto de igualização, estruturado em diversas camadas, visa, justamente, afirmar uma classe que, por outro lado, está sugerindo a abolição de classes. Esta simultaneidade prevê uma instância específica, que responde a uma causa (a do operário), e outra genérica, ampla (que conversa com as demais classes). Ou, nas palavras de Marcuse (1973), uma dialética do universal e do particular:

\footnotetext{
19 "Uma psicanálise das artes plásticas poderia considerar a prática do embalsamento como um fato fundamental de sua gênese." (BAZIN, 2014, p. 27)

${ }^{20}$ No original: Un film écrit, joué et revé par le groupe Medvedkine de Sochaux.

${ }^{21}$ Uma célebre fotografia que retrata em primeiro plano a atriz e modelo Caroline de Bendern, assídua nas produções do grupo Zanzibar, em meio a uma manifestação. Conta-se que a divulgação da fotografia na capa de um periódico teria trazido desgosto à família da atriz, muito conservadora, lhe custando a exclusão de uma herança.
} 
Recordo, uma vez mais, a dialética do universal e do particular no conceito do proletariado; como uma classe na (mas não da) sociedade capitalista, o seu interesse particular (a sua própria libertação) é, ao mesmo tempo, o interesse geral: não pode libertar-se sem abolir-se como classe e abolir todas as classes. Isso não é um 'ideal', mas a própria dinâmica da revolução socialista. Segue-se que as metas do proletariado como classe revolucionária transcendem-se a si próprias: enquanto que permanecem metas históricas, concretas, elas expandem-se, em seu conteúdo de classe, para além do conteúdo específico de classe. E se tal transcendência é uma qualidade essencial de toda a arte, segue-se que as metas da revolução podem encontrar expressão na arte burguesa e em todas as formas de arte. $[\ldots]$

Portanto, não constitui paradoxo nem exceção que mesmo conteúdos especificamente proletários encontrem abrigo na 'literatura burguesa'. Eles são frequentemente acompanhados por uma espécie de revolução linguística, a qual substitui a linguagem da classe dominante pela do proletário - sem destruir a forma tradicional (do romance, do drama). Ou, inversamente, os conteúdos revolucionários proletários são formados na linguagem 'elevada' e estilizada da poesia (tradicional), como na Ópera dos três vinténs e em Mahagonny, de Brecht, e na prosa 'artística' do seu Galileu. (MARCUSE, 1973, p. 120, grifo do autor).

Colocado dessa forma, o argumento de Lukács, lá atrás, a favor de uma literatura integrada à estética burguesa, teria algum respaldo. Mas para a linha sustentada por Marcuse (1973), que defende um âmbito estético de transformação, ele não pareceria tão significativo. Acabaria por proporcionar a distinção entre uma literatura revolucionária e outra proletária, como se vê no comentário reproduzido na epígrafe. Tomando como exemplo os filmes aqui abordados, uma mundivisão proletária nas artes acabaria por assumir uma forma narrativa para veicular a experiência de classe, consolidando a discrepância entre possibilidade e significado de um cinema operário? Tanto Suzanne quanto os operários que toparam encenar as próprias experiências na Peugeot estão jogando nos dois lados. Sabem da importância que carregam ao fazer um cinema proletário se expondo (vanguarda na arte); ao fazê-lo, aderem à forma mágica da narrativa ao assumirem esta encenação. Seja pela via documental, Classe de lutte, seja pela dramatização encenada, Week-end à Sochaux. 0 sorriso de Suzanne e as gags dos operários da Peugeot são complementares, não deixam de estar favorecendo uma representação idealista de si mesmos e da condição proletária, uma harmonia que deixa o longo histórico de lutas algo mais palatável. Estariam em harmonia com a experiência de classe?

Por outro lado, esta fórmula que absorve a mundivisão proletária em uma estética relacionada à burguesa colapsa a natureza irracional, incontrolável, da arte, de justamente não ser o que é racional. Pois, como afirma Marcuse (1973), “A arte só pode expressar o seu potencial radical como arte, em sua própria linguagem e imagem, a qual invalida a 
linguagem corrente, a prose du monde." (MARCUSE, 1973, p. 102, 103 grifo do autor). Visto por esse ângulo, tal produção dos grupos Medvedkine estaria apartada da expressão revolucionária. Seja pelo viés marxista científico - do qual o silêncio da crítica sobre os filmes por si só legitima tal distância, seja pelo viés da aparência estética. Poderia, dessa forma, se assumir que, devido ao forte conteúdo político que justifica por si só a razão de ser de Classe de lutte e Week-end à Sochaux, a transformação estética tenha ficado, ao menos nestas manifestações iniciais, em segundo plano. E mais: que a tradução em linguagem cinematográfica deste cotidiano proletário militante obrigatoriamente tenha resultado em um acabamento artístico mais convencional. Tais fatos exemplificam o alegado problema de autenticidade que ronda o conceito de mundivisão proletária, tal como abordado acima.

Em tal contexto, Marcuse (1973) delimita a diferença entre uma arte revolucionária que é oriunda da classe proletária em países desenvolvidos de uma arte desenvolvida pelas minorias raciais (nestes mesmos países ou no terceiro mundo). A diferença seria estética, e a questão da cultura negra um exemplo recorrente: "rebelião total que encontra expressão na forma estética" (MARCUSE, 1973, p. 124). Neste paralelo, o cinema com "mundivisão proletária" exercido nos dois filmes dos grupos Medvedkine aqui analisados não corresponderia ao que Marcuse (2015) outrora denominou Grande Recusa - conceito que, nas artes, implicaria, entre outras coisas, em um estágio de autocriação. Esta sim, feita pelas minorias e voltada a elas, consiste em uma contradição fundamental: é também particular e, ao mesmo tempo, universal, mas em uma chave estética.

\section{Conclusão}

Classe de lutte e Week-end à Sochaux representam, portanto, o que se apontou no início do texto como a vanguarda no cinema. Simbolizam de forma contundente um esforço concreto de tornar do cinema uma ferramenta democrática de expressão proletária. A frase grafada na parede do centro de produção onde Suzanne milita dá a entender, contudo, que a experiência não se limitaria apenas ao âmbito da prática, mas se estenderia também a uma consciência teórica ("O cinema não é uma magia, ele é uma técnica e uma ciência; uma técnica nascida de uma ciência e colocada a serviço de uma vontade: a vontade que os trabalhadores têm de se libertar."). Ao definir o cinema como oposto à fatura mágica, mas afinado à meta materialista (uma técnica e uma ciência), é difícil encontrar coerência no resultado final. A qual liberação estaria, afinal, referindo-se a vontade dos trabalhadores? A liberdade para a prática destituída de um editorial politicamente consciente ou em vias de 
construção, condenando o cinema operário a um lugar distinto ao de um cinema revolucionário?

A mundivisão proletária que se vê estruturada nos dois filmes abordados pelo texto parece não admitir um potencial estético. Se Marcuse (1973) compreende que no início dos anos 1970 a "negação definitiva" da literatura tida como burguesa era "uma coisa do futuro", como observado no início, tais filmes não vão contrariar a perspectiva se aplicada para o campo cinematográfico. Ao tornar de si mesmos os protagonistas da história, o cinema inaugural dos grupos Medvedkines consolida uma inversão vanguardista plenamente contextualizada pelo espírito do tempo. Mas não vai deixar de soar retrógrado ao incorporar a este protagonismo uma configuração na sintonia da obra orgânica. Dá a ver, mais uma vez, a divergência entre as pretensões científicas e as artísticas; ou entre a prática política e a prática estética; ou, ainda, entre a mundivisão proletária que vem pressuposta (em uma literatura proletária, no discurso trazido por Gallas (1974), mas adaptado aqui para o cinema) e a verificação dela.

Será necessário ainda acompanhar os desdobramentos da filmografia destes grupos, mais particularmente o de Besançon, para redimensionar o foco do trabalho. Uma considerável mudança irá se dar, alargando a compreensão de uma mundivisão proletária no cinema e do que poderá ou deverá ser compreendido como "ferramenta de conhecimento e tomada da palavra" proletária. 0 trabalho proposto aqui, contudo, se limita a abrir uma discussão sobre a largada deste projeto que uniu a fome de cineastas afeitos à pauta revolucionário-militante à vontade de comer daqueles que se viram instigados diante de uma nova linha de montagem.

\section{Referências}

À BIENTÔT, j'espère. Direção: Chris Marker e Mario Marret. Paris: S.L.O.N., 1967. 1 DVD (43 $\min ), \mathrm{p} \& \mathrm{~b}, 16 \mathrm{~mm}$.

ALBERA, François. Modernidade e vanguarda do cinema. Rio de Janeiro: Azougue, 2012.

BAZIN, André. 0 que é o cinema? São Paulo: Cosac Naify, 2014.

BRITISH sounds. Direção e produção de Grupo Dziga Vertov. Londres: Grupo Dziga Vertov, 1969. 1 DVD (52 min), color., $16 \mathrm{~mm}$.

BÜRGER, Peter. Teoria da vanguarda. São Paulo: Cosac Naify, 2008. 
CLASSE de lutte. Direção: Grupo Medvedkine de Beçanson. Produção: S.L.O.N. Paris: S.L.O.N., 1969. 1 DVD (39 min), p \& b, $16 \mathrm{~mm}$.

COMOLLI, Jean-Louis. Ici et maintenant, d'un cinéma sans maître. In: COMOLLI, Jean-Louis; LEBLANC, Gérard; NARBONI, Jean. Cinéma et politique: 1956-1970 (Les années pop). Paris: BPI, 2001. p. 33-58.

ESTEVES, Leonardo Gomes. Apontamentos sobre a prática teórica no cinema pós-68 aventada pela crítica. Eco Pós, Rio de Janeiro, v. 21, n. 1, p. 202-220, 2018.

ESTEVES, Leonardo Gomes. Dialéticas da desconstrução: Maio de 68 e o cinema. 2017. Tese (Doutorado em Comunicação Social) - Departamento de Comunicação Social, Pontifícia Universidade Católica do Rio de Janeiro, Rio de Janeiro, 2017.

FARGIER, Jean-Paul. La parenthèse et le detour: essai de définition théorique du rapport cinéma et politique. Cinéthique, Paris, n. 5, p. 15-21, 1969.

FOLTZ, Colin. L'expérience des groupes Medvedkine (S.L.O.N. 1967 - 1974) histoire d'une aventure cinématographique révolutionnaire. 2001. Mémoire (Maîtrise en Études Cinématographiques) - Université Paris 1 Panthéon Sorbonne, Paris, 2001.

FRANCO, Renato Bueno. Ficção e política no Brasil: os anos 70. 1992. Tese (Doutorado em Teoria Literária) - Instituto de Estudos da Linguagem, Universidade Estadual de Campinas, Campinas, 1992.

GALLAS, Helga. Teorie marxiste della letteratura. Roma: Editori Laterza, 1974.

ICI et ailleurs. Direção: Jean-Luc Godard e Anne-Marie Miéville. Produção: Jean-Pierre Rassan, Jean-Luc Godard e Anne-Marie Miéville. Paris: Sonimage, 1974. 1 DVD (50 min), color., $16 \mathrm{~mm}$.

LEBLANC, Gérard. Cinéthique [mensagem pessoal]. Mensagem recebida por leonardogesteves@gmail.com em 11 mar. 2017.

MARCUSE, Herbert. A arte na sociedade unidimensional. In: LIMA, L. C. (org.). Teoria da cultura de massa. São Paulo: Paz e terra, 2002. p. 288-302.

MARCUSE, Herbert. Contra-revolução e revolta. Rio de Janeiro: Jorge Zahar, 1973.

MARCUSE, Herbert. 0 homem unidimensional. São Paulo: Edipro, 2015.

MUEL, Bruno; MUEL-DREYFUS, Francine. Week-ends à Sochaux (1968-1975). In:

DAMAMME, D. et al. (org.). Mai-Juin 68. Paris: Les Éditions de l'Atelier, 2008. p. 329-343.

RANCIÈRE, Jacques. La leçon d'Althusser. Paris: La Fabrique Éditions, 2011.

TUDO vai bem. Direção: Jean-Luc Godard e Jean-Pierre Gorin. Paris: Gaumont, 1972. 1 DVD (96 min), color., $35 \mathrm{~mm}$.

WEEK-END à Sochaux. Direção e produção de Bruno Muel e Groupe Medvedkine de Sochaux. Sochaux: S.L.O.N., 1972. 1 DVD (57 min), color., 16 mm.

XAVIER, Ismail. 0 discurso cinematográfico. São Paulo: Paz e terra, 2005. 


\title{
Proletarian world view in Medvedkine groups cinema.
}

\begin{abstract}
This article aims to investigate the initial films of the Medvedkine groups, created in Besançon and Sochaux during the late 1960's and composed by factory workers. The proletarian world view concept, brought by philosopher Herbert Marcuse in Counterrevolution and revolt, is taken as a parameter in this analisis. The films targeted in this study are: Classe de lutte (1969) and Week-end à Sochaux (1972). Regarding these titles, one wishes to analyze the convergences and discrepances between this initial filmography and the avant-garde standards, divided between social protagonism and aesthetic denial, in order to sculpt a comparative view among theory and practice over a filmmaker craft played by the proletarian. One comes to a conclusion that there are disagreements between the object of this review and an avant-garde cinema wich is elaborated during that period.
\end{abstract}

\section{Keywords}

French Cinema. Avant-garde cinema. Militant cinema. Medvedkine groups. May 68.

Recebido em 30/04/2019

Aceito em 19/08/2019 